\title{
Application of blockchain technology in accounting and audit: international and domestic experience
}

\author{
Mariia Nezhyva ${ }^{1, *}$, Olha Zaremba ${ }^{1, * *}$, and Viktoria Nehodenko, ${ }^{1, * *}$ \\ ${ }^{1}$ Financial analysis and audit department, Kyiv National University of Trade and Economics, 19 Kyoto Str., Kyiv, 02156, Ukraine
}

\begin{abstract}
The article is devoted to the study of blockchain technology in the financial sphere of Ukraine, as well as accounting and audit of their application in domestic and international practice. The article contains data on the prospects of blockchain development in the world and in Ukraine, as well as information on the peculiarities of the use of such technologies in the perspective areas - accounting and audit. The article argues that the development of blockchain technology will enable the transition to more modern methods and techniques, which in turn will allow to modernize the accounting and auditing system. The principle of triple entry as a major component of blockchain technology in accounting is emphasized. One of the most promising areas of application of blockchain is accounting for accounts payable and receivable, tax accrual and payment, record keeping and documentation. The article highlights the advantages and disadvantages of using blockchain technology in the financial sphere of Ukraine.
\end{abstract}

\section{Introduction}

Given the current development of the information environment, the question of improving information technologies and their application in the enterprise management system to increase the competitiveness of economic entities is particularly acute. This necessitates an increase in the cost of IT technology, the introduction of innovation and the broad informatization of the business environment.

Among the advanced technologies of the last decade, the most important is the blockchain technology, which is implemented in various fields, including financial. The experience of scientists and practitioners suggests that the use of blockchain technology in accounting and audit will directly improve these processes, in particular, change the work of an accountant. This will happen through the introduction of modified methods and techniques of information processing, its distribution, as well as dramatically change the very basis of the accounting system. However, there are a number of unresolved problems, as blockchain is currently in the experimental stage of development. This determines the need to improve this issue and accordingly determines the relevance of the topic under study.

The term "blockchain" has been introduced not so long ago in the economic literature. It was only after 2014 that blockchain publications began to appear in the economic literature. We study the peculiarities of the use of blockchain technology in the works [119]. Ukrainian enterprises have been slow to adapt their accounting and auditing systems to modern information technologies. Therefore, modern blockchain technology

\footnotetext{
*e-mail: marijka@ukr.net

**e-mail: olga.zaremba@midland-development.com.ua

***e-mail: vikla1977@ukr.net
}

is in its infancy. This is explained by the limited scientific work of a methodological nature, which deals with the prospects of blockchain development, its advantages and disadvantages.

The purpose of the article is to determine the role of modern blockchain technology in financial areas, in particular in the field of accounting and audit, to study the results of implementation of this technology in foreign countries and to identify promising areas of development for Ukraine.

\section{Results}

A positive moment for the development of the blockchain was the approval of the Concept of Digital Economy Development [20]. This Concept is designed to encourage the digitization of all areas of economic activity, stimulate the use of digital technologies in enterprises and indicates the priority of the development of these technologies at the state level. Consider the key strategic goals facing Ukraine in the run up to 2030:

- increase the nominal GDP of Ukraine by 8 times - up to 1 trillion dollars in 2030;

- become an influential regional entity, independent, independent in making economic and geopolitical decisions, as far as the global situation will make it possible;

- ensure higher-than-average incomes and quality of life of Ukrainians in Europe and neighboring countries (nominal average monthly salary in 2030 is not lower than 2700 dollars; average monthly pension is 775 dollars);

- create conditions for the growth of capitalization of Ukrainian business; 
- create conditions for an 8-10-fold increase in the economy over the next 10 years;

- significantly increase labor productivity (according to UIF estimates, to reach a GDP of 1 trillion dollars, productivity should increase 8.5 times to 71,000 dollars per employee. This is in line with the current level of productivity in high-tech sectors such as Belgium, Denmark, Finland, Germany, Sweden);

- make a technological leap in the Ukrainian economy;

- significantly increase the competitiveness of the Ukrainian economy in global markets;

- create new business models, new segments and sectors, opportunities to quickly, conveniently, cheaply develop, scale and capitalize any business;

- create new jobs, demand for new professions.

The main effect of digitalization is to change the value chains [21, 22]. Technology and digitalization will displace people from their usual processes - production, services, entertainment, trade, education and even medicine [23]. At the same time, the return on investment in business will dramatically increase. According to Digital Spillover [24], the ROI for digital technologies is 6.7 times higher than for traditional ones. According to research in the Digital Spillover report, every dollar invested in digital technology causes GDP growth of 20 dollars, ie the investment multiplier is 20 . For comparison: the multiplier of traditional investment (non-digital) is 2-8 (depending on the industry).

Data becomes an asset. Collection, description, storage and processing of data allow to obtain valuable information for use in business processes, public life, the work of the state. The ability to work with data and analyze it is an opportunity to be the first to receive valuable market "insights", ie to be more competitive. Data is accessed via the Internet and other networks. Much of the world's data is (or has become) open.

Digital technologies have become the basis for the creation of new products, values, properties and, consequently, the basis for gaining competitive advantage in most markets. Digitization has given small companies and project teams the opportunity to create new products and quickly bring them to market along with the large companies present there. This led to the shift of "innovation centers" from large companies to small ones (startups, etc.). Digital transformation leads to the emergence of new unique systems and processes that make up their new value essence (e.g., Uber, Airbnb, digital banking, etc. [25-30]).

The world economy is significantly affected by business models of the common economy, or the sharing economy, which operates on the basis of digital technologies. The sharing economy includes living together (sharing), car sharing, offices (coworking), gadgets, clothes and even food (food sharing - "saving" products intended for disposal in the interests of the needy). Part of this trend is cloud technology [31].

Virtualization makes it possible to significantly reduce the initial capital cost of deploying the necessary digital infrastructure through the use of cloud technologies and software-defined architecture. Technology allows you to rent computing capabilities and services based on the needs of a particular business process. The user has the ability to quickly access the service and rent for the required time the required capacity on secure and technological platforms.

The use of artificial intelligence [32] is spreading to more and more areas and sectors of the economy. The number of companies that use it to one degree or another is growing exponentially. Countries are developing national artificial intelligence strategies and trying to compete with each other for talent. Ethical norms and limits of use are defined. Today, artificial intelligence combines many technologies, the main of which are: machine learning [33], computer vision [34], deep learning [35] and natural language processing (NLP) [36]. Artificial intelligence based on the processing of large data sets allows you to optimize processes and improve the quality of digital products and services.

Over the last 10 years, digitalization has become a key driver of growth in the Ukrainian economy and the wellbeing of citizens. Today, every Ukrainian can easily capitalize on themselves, their skills, knowledge through the use of digital technologies. With a smartphone and Internet access, everyone was able to sell their services through online services without intermediaries and employers; create a business from scratch without start-up capital and assets; receive income from the realization of their creative potential and creative ideas. Ukraine has become an intellectual hub, where all conditions are created for the development of people's potential.

In Ukraine, the principle of digital by default applies all spheres of public life services are permeated by digitalization. The maintenance and development of any physical system occurs only in the absence of a digital alternative. $95 \%$ of all companies have changed their business models and goals under the influence of new technologies. Those who did not have time to do so, remained outsiders or disappeared altogether.

Digitization has made it possible to: optimize business processes; create new products and services thanks to the Internet of Things technology, virtual reality, cloud services, artificial intelligence; reduce costs (savings on people through automation and robotics, accounting automation, "smart" supply and fleet management, control over fuel consumption); offer completely new business solutions: new insurance models, P2P systems, alternative banking services, mobile training applications, individual approach to the online buyer, personal advertising [3741].

Today, companies work at the intersection of industries and segments, becoming platforms and platforms, where they offer their customers not just a product, but the solution of any problems, gaining experience, values, emotions and impressions.

One of the most important values for the development of the digital economy is data [42]. Access to public, professional, industrial and other data is an important tool for the emergence of new products and services, i.e. directly affects economic growth. 
Data is the basis of many digital services and products, working with large arrays helps to make research and development work more efficient and effective, more dynamically with the availability of data, develop technologies of artificial intelligence and predictive analytics. To take full advantage of the analysis, Big Data must be available [43].

Open non-personal data should be of better quality in a form suitable for processing, indicating the main indicators (data legends).

The government also needs to encourage and create conditions for the exchange of data between private sector companies, while ensuring the security and confidentiality of such data. For example, to introduce tax benefits or make priority partners of the company, ready to share non-personal data with other companies through government digital platforms. The idea of paying taxes with data should be considered as an incentive.

You also need to keep in mind that data sharing can be costly for its owners. This can reduce incentives to ensure data transmission and raise the question of who should bear the costs of developing and maintaining transmission mechanisms. Therefore, government initiatives that facilitate data transfer may be needed. In the EU, for example, data exchange between companies began with the development of codes of conduct for suppliers.

The state, in turn, can create secure digital platforms for storing, transmitting, and administering citizens' data. Such platforms will allow citizens to manage their data and configure access rights to it by public institutions and private companies. In addition, the state needs to develop rules for managing personal data for users on such platforms. An example is the joint project of Amsterdam and Barcelona, funded by the European Union - DECODE. It is a digital blockchain platform that allows the user to set rules for the use of his data.

An important issue in working with data is the degree of their protection. This is what the state should focus on when creating digital platforms and providing access to personal but not personalized data. The higher trust of citizens, the greater their willingness to share their information.

The state needs to open access to any of its data that does not relate to national security issues and does not violate the right of citizens to privacy. Another function of the state in working with data should be training programs for entrepreneurs and researchers on what data from government agencies are, where to find them, how to work with them. Public authorities and companies themselves should also increase their competencies in data science and artificial intelligence.

Large-scale digitalization of spheres of life will lead to the fact that citizens of Ukraine and business will increasingly suffer from the growth of cybercrime. For example, when shopping or doing banking online.

The most dangerous for the economy and citizens are cyber attacks on critical infrastructure (energy, transport management, banking and telecommunications sectors, health care, water supply, etc.).
Finally, increasingly sophisticated and interconnected digital technologies will lead to new forms of cyberattacks (zero-day vulnerabilities).

Ukraine and its specialized organizations should work with all stakeholders, especially at the European level, to ensure national cybersecurity and cyber defense. The development of technical and organizational solutions should, on the one hand, not limit the opportunities offered by the country's transition to digital technologies, and on the other hand - to ensure the appropriate level of trust and security for each user.

In 2008, Satoshi Nakamoto highlighted the principles of blockchain technology in his work called "Bitcoin: A Peer-to-Peer Electronic Cash System" [44]. The basis of the blockchain is the principle of information exchange in peer network (Peer-to-Peer, P2P), which does not need for the functioning of the central server [2].

It is impossible to study the peculiarities of the implementation of blockchain technology, including accounting and audit, without understanding the very essence of this latest technology. There are different approaches to interpreting blockchain. For example, the founder of the Blockchain Research Institute in England, M. Swan interprets blockchain technology as a multifunctional and multilevel information technology designed to securely account for various assets; it is a decentralized transparent transaction record book - a database updated and controlled by participants [4].

In a general sense, a blockchain is a chain consisting of a large number of blocks, each containing a variety of information. Each subsequent block contains information about the previous one in encrypted form. The uniqueness of this technology is that the entire data register is decentralized (figure 1), and its copies are stored simultaneously on tens of thousands of computers around the world. This provides the highest level of protection against external influences. The data contained in the system cannot be deleted or replaced. Such a database is characterized by anonymity, an agreed mechanism, it is not owned by a specific entity, is not controlled or regulated by third parties. All functions in a blockchain system are distributed among its members, who pre-approve changes that may occur in the system. Thus, it is virtually impossible to make changes and edit after the transaction. The above information proves the ideal of blockchain technology for accounting purposes, because it monitors all transactions and changes in the system, prevents manipulation and distortion.

There are different types of blockchain, the classification of which is shown in figure 2. The level of access is open, closed and consortium blockchain. The peculiarity of open blockchain is that absolutely anyone can join the public network. The participant has the opportunity to read, add new entries and participate in blockchain processes. There is no external control in the open type. Closed blockchain, in turn, requires permissions for user access, imposes various restrictions, there is control over who exactly has the right to become a member of the network and in what transactions can participate. 


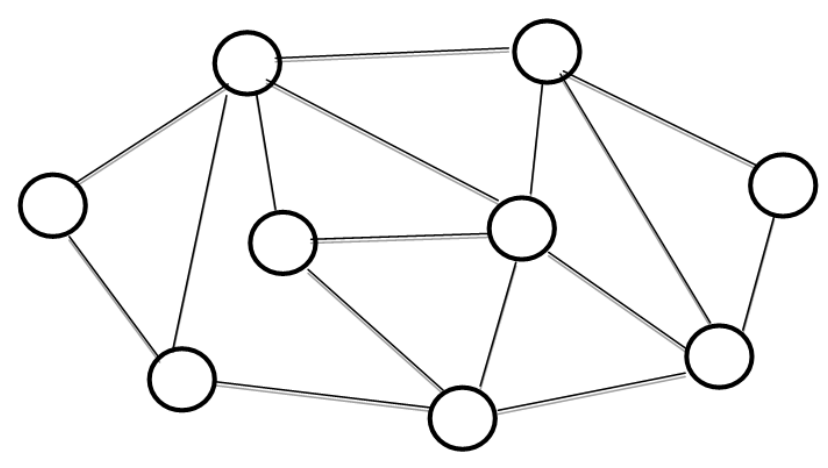

Figure 1. Decentralized principle of blockchain technology

Permissionless blockchain does not have a supervisory authority that validates transactions. This includes all known cryptocurrency platforms. The meaning of such data processing is the lack of benefits for any participant in the process of the operation. The use of open blockchain technology can serve to create a truly democratic system.

Permissioned blockchain is the confirmation of transactions by certain persons, in which the employee, the enterprise, the state can act. Participants have the ability to read system data, but some information may not be available. Regular users cannot enter data.

There are different categories of Blockchain 1.0-5.0 (the last two currently have only theoretical character). Blockchain 1.0 is a cryptocurrency that is used in various applications (such as wire transfer, digital payments). In turn, Blockchain 2.0 is contracts. Entire classes of economic, market, and financial applications based on blockchain work with different types of financial instruments (stocks, bonds, futures, smart assets, smart contracts). Blockchain 3.0 is an application whose scope goes beyond cash calculations. They extend to the spheres of public administration, health care, science, education, culture and the arts.

According to the Deloitte Digital-funded Coming of Age Digitally report, as well as PwC research, in 2018, $84 \%$ of respondents (600 business executives) are somehow involved in the blockchain process, and 30 percent of respondents (over 4,300 managers, executives) and analysts around the world point to the maturity of digital technology in their organizations, with the adoption of such technologies changing the speed, creativity, learning, risk, collaboration, quality of decision making, transparency, etc. for the better. In turn, 53\% of companies say that blockchain technology is one of their top five strategic priorities in 2019, up 23.3\% from the previous year [45].

There are some issues that adversely affect the competitiveness of companies that use blockchain technology. Among them, the expected rate of return on digital technology, which is $3-5$ years, which is considered a long enough business.

The blockchain that recently started to be actively used in finance and accounting is still in its infancy, as stated in the 2018 KPMG report. Statistics show that only $1 \%$ of businesses use it at the mature level, while $74 \%$ of businesses say full maturity of blockchain. However, by 2021, at least $25 \%$ of the world's largest public companies are projected to use blockchain, with a value added to 176 billion dollars USA by 2025 [46].

According to research by one of the leading experts in blockchain technology in the world, Tapscott, Ukraine belongs to the 14 leading countries in the implementation of blockchain technology, among which the first are the USA, Canada, Brazil, Australia and Israel. Currently, the US is the leader, but China is forecast to be the leader in 2021-2023 [47].

Table 1. Opportunities for the impact of blockchain technology on accounting and audit

\begin{tabular}{ll}
\hline $\begin{array}{l}\text { Characteristics } \\
\text { of blockchain } \\
\text { technology }\end{array}$ & Impact on accounting and audit \\
\hline $\begin{array}{l}\text { Distributed } \\
\text { Book }\end{array}$ & $\begin{array}{l}\text { The parties to the transaction share } \\
\text { information about its implementation, } \\
\text { by confirming one or another trans- } \\
\text { action increases the confidence that } \\
\text { it will take place on the terms ap- } \\
\text { proved in the contract, facilitates in- } \\
\text { teraction between the parties without } \\
\text { paper workflow }\end{array}$
\end{tabular}

Real-time up- Accounting transactions are recorded dates in real time, information about them appears immediately on all sides of the contract, which allows for operational accounting and control

Confirmed, Since business transactions, once valprotected idated by the parties, are recorded and digi- on the system by means of a cryptotally signed graphic hash, it is practically impossiagreements ble to make irregular adjustments and changes to the accounting records after the fact

Consensus Transactions are updated only by agreement between the parties, which minimizes the fact of non-fulfillment of contractual obligations

Irreversibility Increased security of accounting data, reliability of records of performed business transactions

Transparency Availability of accounting information including auditors, continuity and ease of audit

Triple entry The method of accounting for the part of the double entry changes, which is supplemented by the third one confirmation of the transaction in the blockchain

In Ukraine, there is no regulatory framework governing blockchain technology. The Law of Ukraine "On the Circulation of Cryptocurrency in Ukraine" is at the stage of the project, and the National Bank of Ukraine in its explanation considers bitcoin as a money surrogate forbidden to use in the territory of Ukraine [48]. There is ongoing debate in the scientific space as to whether it is nec- 


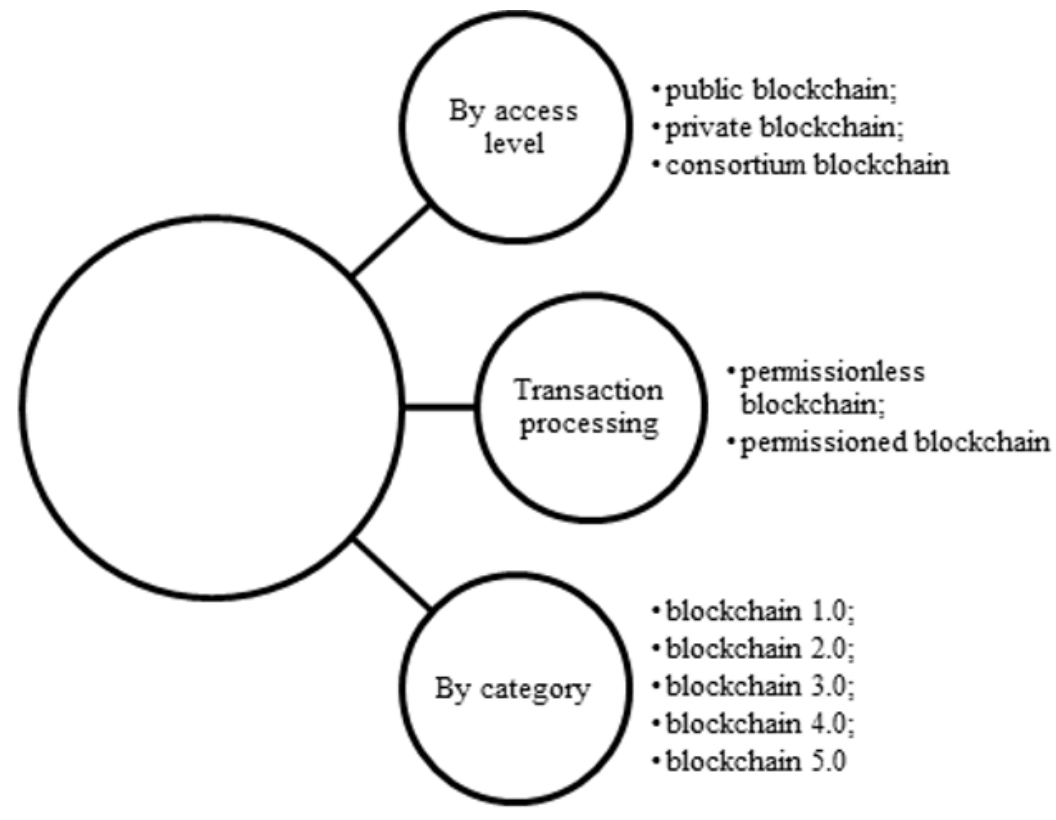

Figure 2. Classification of Blockchain technology

essary to legislate on this topic. On the one hand, lawlessness persists, which in turn can generate fraudulent schemes. On the other hand, state regulation of blockchain technology is able to establish uniform rules that must be observed by all market participants. However, additional burdens may be imposed on states. That is, there is a debatable nature of uncertainty.

Today, in Ukraine, obsolescence of the methods and techniques on which accounting and auditing is based is obsolete, the inconsistency of these methods with the digital economy of today, the basis of which is occupied by information technologies. Upgrading requires technology for processing, storing, transmitting and accumulating information. Therefore, blockchain technology is the main motive for the development and modernization of the entire accounting and audit methodology.

Blockchain technology allows participants to share data for each transaction that requires accounting records. By using blockchain, parties can set read-only mode specifically for external users, such as auditors and government agencies. Such access enables the transaction to be confirmed instantly for the purpose of reporting and other regulatory purposes. As a result, the work of the auditor will be automated, uninterrupted, more accurate and analytically disclosed. The introduction of blockchain technology in accounting and audit will reveal their processes in real time, meaning users will not have to wait for the end of the reporting period.

Creating a system of stable accounting - a common registry, its cryptographic coding virtually impossible to falsify, destroy data or hide activity. Blockchain technology can be combined with an existing accounting system in the form of a local blockchain within a single enterprise or group of companies. Today, some companies are implementing blockchain for certain types of transactions.
Currently there are no enterprises with complete transformation of processes into blockchain technology.

There are features of blockchain technology such as: distributed ledger, triple entry (the main feature, while accounting uses dual entry), real-time updates, transparency, irreversibility, and more. All of them have a direct impact on accounting and auditing. The possibilities of such influence are shown in table 1 [5].

The application of blockchain technology in accounting is in the most promising areas, the main of which are payments with counterparties (accounts receivable and payables, including international purchases and transactions). There is also the use of this technology in operational accounting and reporting, when handling documents and storing them. The movement of assets within the enterprise, the calculation of taxes and their payment are increasingly accounted for by enterprises using blockchain technology.

Today, blockchain is increasingly popular in the audit field. In particular, the Big Four companies Deloitte and $\mathrm{PwC}$ are actively introducing blockchain technology into accounting practices.

In the field of audit Redchenko [3] identifies two areas of blockchain technology development: application in accounting systems to provide assurance or fulfillment of financial reporting procedures agreed with the client; providing services to companies that use blockchain in their own activities. The implementation of blockchain technology necessitates the continuous training of auditors and accountants, the continuous improvement of their knowledge in the field of information technology. The result of applying new technologies, like any phenomenon, has its advantages and disadvantages.

In the business environment, opinions are also divided on the feasibility of implementing blockchain technology in accounting and auditing. Many members of the business 
community are convinced that at this embryonic stage, it is difficult to understand the full meaning and power of new technologies. Note that for the effective and easy introduction of blockchain technology, you also need to improve the skills of employees in accounting and auditing, as well as to change business models in enterprises, which requires additional costs.

\section{Conclusions}

Thus, the implementation of blockchain technology in accounting and audit, according to most scientists, is a promising direction for improving this field. Investigating this issue, we can conclude that blockchain technology is developing at a rapid pace in various manifestations. This technology is transforming some of the outdated accounting and audit methods. Advantages of its introduction at the enterprise are reduction of expenses for keeping of accounting, carrying out of audit, increase of access to the information, its more reliable protection, unnecessary keeping of documentation in a manual way, in paper form. Blockchain improves relationships with contractors and extends enterprise access to finance. However, there are some doubts, including the overload of carriers with a wealth of information, the possibility of cyber attacks, the negative impact on the environment. Only through a comprehensive analysis, evaluation of all factors influencing management personnel can determine the feasibility of introducing blockchain technology in accounting and audit at the enterprise.

\section{References}

[1] J.L. Zhao, S. Fan, J. Yan, Financial Innovation 2, 28 (2016)

[2] A. Porytko, Debit Credit 37 (2017)

[3] K. Redchenko, Statistics of Ukraine 1, 85 (2018)

[4] M. Swan, Blockchain: Blueprint for a new economy (O’Reilly Media, Inc., 2015)

[5] L. Rao, S. Pandurangiah, The Management Accountant 53, 42 (2018)

[6] M. Iansiti, K.R. Lakhani, The truth about blockchain (2017), https://hbr.org/2017/ 01/the-truth-about-blockchain

[7] R. Wattenhofer, The science of the blockchain (2016), https://lib.hpu.edu.vn/handle/ $123456789 / 28113$

[8] N. Yushchenko, Economy and Management of National Economy 19, 269 (2018)

[9] D. Tapscott, A. Tapscott, Business and the World pp. 269-275 (2016)

[10] P. Boucher, S. Nascimento, M. Kritikos, How blockchain technology could change our lives (Scientific Foresight Unit, Brussels, 2017), https://www . europarl . europa.eu/RegData/ etudes/IDAN/2017/581948/EPRS_IDA(2017) 581948_EN.pdf
[11] B. Marr, How blockchain technology could change the world (2016), https://tinyurl.com/ 9d3drn35

[12] J. Buchan, Blockchain technology review - industry applications (2017), http://web.archive.org/web/ $20210225021349 /$ https: //zudu.co.uk/blog/ blockchain-technology-industry-applications /

[13] O. Boyko, Global and national problems of economy 22, 31 (2018)

[14] A. Litoshenko, Economic analysis 23, 88 (2016)

[15] A. Litoshenko, Economy and state 8, 77 (2017)

[16] D. Efanov, P. Roschin, Procedia Computer Science 123, 116 (2018)

[17] N. Kshetri, Telecommunications Policy 41, 1027 (2017)

[18] M. Nezhyva, V. Miniailo, Herald of Kyiv National University of Trade and Economics 3, 123 (2020)

[19] V. Soloviev, A. Belinskiy, Communications in Computer and Information Science 1007, 276 (2019)

[20] On approval of the concept of development of the digital economy and society of ukraine for 20182020 and approval of the action plan for its implementation (2018), https: //zakon. rada.gov.ua/ laws/show/67-2018-\%D1\%80\#Text

[21] O. Kravchenko, M. Leshchenko, D. Marushchak, Y. Vdovychenko, CEUR Workshop Proceedings 2422, 434 (2019)

[22] H. Kucherova, D. Ocheretin, V. Los, N. Venherska, CEUR Workshop Proceedings 2732, 385 (2020)

[23] I.K. Pokulyta, M.O. Kolotylo, Journal of Physics: Conference Series 1840, 012055 (2021)

[24] Digital Spillover: Measuring the true impact of the digital economy (2017), https://www.huawei. com/minisite/gci/en/digital-spillover/ files/gci_digital_spillover.pdf

[25] D. Trcek, CEUR Workshop Proceedings 2422, 263 (2019)

[26] O. Kuzminska, M. Mazorchuk, N. Morze, O. Kobylin, CEUR Workshop Proceedings 2393, 53 (2019)

[27] O. Pinchuk, O. Sokolyuk, O. Burov, M. Shyshkina, CEUR Workshop Proceedings 2433, 90 (2019)

[28] A. Iatsyshyn, V. Kovach, Y. Romanenko, A. Iatsyshyn, CEUR Workshop Proceedings 2433, 197 (2019)

[29] M.P. Leshchenko, A.M. Kolomiiets, A.V. Iatsyshyn, V.V. Kovalenko, A.V. Dakal, O.O. Radchenko, Journal of Physics: Conference Series 1840, 012057 (2021)

[30] N.V. Morze, O.V. Strutynska, Journal of Physics: Conference Series (2021)

[31] O. Markova, S. Semerikov, A. Striuk, H. Shalatska, P. Nechypurenko, V. Tron, CEUR Workshop Proceedings 2433, 499 (2019)

[32] O. Haranin, N. Moiseienko, CEUR Workshop Proceedings 2292, 143 (2018) 
[33] A. Kiv, V. Soloviev, S. Semerikov, H. Danylchuk, L. Kibalnyk, A. Matviychuk, CEUR Workshop Proceedings 2422, 1 (2019)

[34] M. Bogdanovskyi, A. Tkachuk, O. Dobrzhanskyi, A. Humeniuk, E3S Web of Conferences 166, 05004 (2020)

[35] V. Derbentsev, A. Matviychuk, N. Datsenko, V. Bezkorovainyi, A. Azaryan, CEUR Workshop Proceedings 2713, 434 (2020)

[36] K. Osadcha, V. Osadchyi, S. Semerikov, H. Chemerys, A. Chorna, CEUR Workshop Proceedings 2732, 547 (2020)

[37] I. Mintii, V. Soloviev, CEUR Workshop Proceedings 2257, 227 (2018)

[38] S. Symonenko, N. Zaitseva, V. Osadchyi, K. Osadcha, E. Shmeltser, CEUR Workshop Proceedings 2547, 37 (2020)

[39] M. Volikova, T. Armash, Y. Yechkalo, V. Zaselskiy, CEUR Workshop Proceedings 2433, 486 (2019)

[40] V. Tkachuk, S. Semerikov, Y. Yechkalo, S. Khotskina, V. Soloviev, CEUR Workshop Proceedings 2732, 1058 (2020)

[41] A. Vinkovska, A. Kiv, T. Koycheva, L. Bodnar, I. Donchev, CEUR Workshop Proceedings 2422, 274 (2019)

[42] I. Gernego, L. Petrenko, M. Dyba, V. Tsarov, E3S Web of Conferences 166 (2020)
[43] S. Semerikov, I. Teplytskyi, Y. Yechkalo, O. Markova, V. Soloviev, A. Kiv, CEUR Workshop Proceedings 2393, 833 (2019)

[44] S. Nakamoto, Tech. rep. (2008), https: //downloads. coindesk. com/research/ whitepapers/bitcoin.pdf

[45] Deloitte's 2019 global blockchain survey: Blockchain gets down to business (2019), https://www2.deloitte.com/content/ dam/Deloitte/se/Documents/risk/DI_ 2019-global-blockchain-survey.pdf

[46] KPMG, Blockchain and the Future of Finance: A Potential New World for CFOs - and How to Prepare (2018), https://assets. $\mathrm{kpmg} / \mathrm{content} / \mathrm{dam} / \mathrm{kpmg} / \mathrm{ca} / \mathrm{pdf} / 2019 / 05 /$ blockchain-and-the-future-of-finance . pdf

[47] PwC, Blockchain is here. What's your next move? PwC's Global Blockchain Survey 2018 (2018), https://www.pwc.com/jp/ja/knowledge/ thoughtleadership/2018/assets/pdf/ blockchain-in-business-en.pdf

[48] National Bank of Ukraine, Clarification on the lawfulness of the use of "virtual currency / cryptocurrency" bitcoin in ukraine (2014), https://zakon. rada.gov.ua/laws/show/n0435500-14 